\title{
Erratum to: Signal limitations in tip-enhanced Raman scattering: the challenge to become a routine analytical technique
}

\author{
Samuel Berweger • Markus B. Raschke
}

Published online: 24 December 2009

(C) Springer-Verlag 2009

Erratum to: Anal Bioanal Chem

DOI 10.1007/s00216-009-3085-1

Following online publication of the article, the authors found a typographical error in Eq. 2. The correct equation reads:

$\Gamma_{\text {coll }}=\frac{1}{2}\left(1-\sqrt{1-\left(\frac{N A}{n_{\mathrm{i}}}\right)^{2}}\right)$.

All calculations presented in the article were based on this correct form of Eq. 2.

The online version of the original article can be found at http://dx.doi. org/10.1007/s00216-009-3085-1.

S. Berweger $\cdot$ M. B. Raschke $(\bowtie)$

Department of Chemistry, University of Washington,

Seattle, WA 98195, USA

e-mail: raschke@chem.washington.edu 